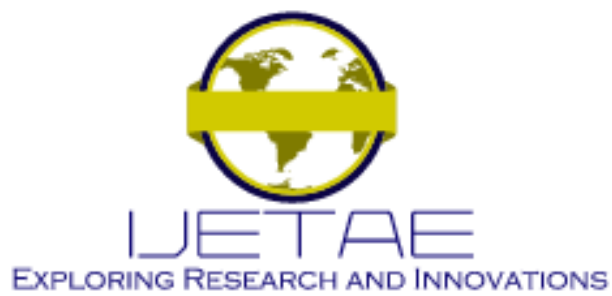

International Journal of Emerging Technology and Advanced Engineering

Website: www.ijetae.com (E-ISSN 2250-2459, Scopus Indexed, ISO 9001:2008 Certified Journal, Volume 11, Issue 07, July 2021)

Manuscript Received: 04 June 2021, Received in Revised form: 30 June 2021, Accepted: 05 July 2021

DOI: 10.46338/ijetae0721_05

\title{
Project Performance Analysis Using Hierarchical Clustering Method
}

\author{
Marian Halaj \\ Faculty of Management of the Comenius University in Bratislava, Odbojarov 10, 831 04, Slovakia
}

\begin{abstract}
This paper deals with the project management performance analysis in automotive industry and usage of the advanced analytics to optimize the performance of the engineering projects within the vehicle manufacturing facility. The aim is to identify and mitigate the common causes of project delay (slippage) in various engineering projects that are independent of the technical discipline where a particular project belongs to. We have used the hierarchical clustering technique here to identify the sub-groups of similar projects and further deeply analysed those ones with the highest average slippage.
\end{abstract}

Keywords-Cluster analysis, Data, Delay, Distance, Hierarchical clustering, Metric, Project, Slippage, Strategy

\section{INTRODUCTION}

The study presented within this paper is driven by the practical need to optimize the overall project delays and resource utilization within the engineering department of the world class luxury vehicles manufacturer, particularly in his subsidy located in the western part of Slovakia. The company is recognized due to its long-term history and iconic models equipped with the state-of-the-art electronic systems. Although the plant operates as a serial production there is a high level of customization, causing task planning and prioritization, or any change control to be extremely complex. The idea behind the study is to find the issues and processes causing delays independently of the functional department involved. On the other hand, some projects may be completed ahead of schedule means the corporate resources are not utilized efficiently either. Knowing these patterns may help company to formulate, implement and verify their business strategies. Both the departmental strategies (functional ones) and even the corporate ones as the improved engineering performance may pull the product quality and reduce the costs

Within the analytical part we have used the advanced business intelligence (BI) tools and techniques, particularly the cluster analysis to identify the groups of apparently similar projects, called clusters.
Knowing of and deeper technical survey on membership within such clusters would allow us to search for the common sources of project slippage within the engineering projects in automotive engineering. We assume the business process sources that are independent of any technical discipline and therefore, applicable for a business transformation across the whole company.

\section{LITERATURE REVIEW}

As already indicated in the introductory chapter this paper deals with the industrial project management and optimization of overall slippage within the large set of various complex projects. By project we mean a unique set of activities meant to produce a defined outcome within an established time frame using specific allocation of resources [1]. This formal definition can be basically translated as a specific engineering problem solving (product) with the limited resources and within specified timeframe. This trade-off is known in project management as a triple constraint [2]. [3] adds another dimension to this problem called ancillary objectives, where he claims the project must also fit to the existing organizational processes. Based on the above definitions we can generally reframe the problem of project management performance as the optimization task where we search for optimum solution within the constraint given by four variables. Theoretically, any optimization can be perceived as a mathematical task of minimizing the utility function. In real world, however the amount of information is limited, therefore the focus is put on decision-making process instead. Here the advanced analytics takes a role.

The recent studies on analytics implementation in decision-making process [4], [5], [6], [7] put the emphasis on using statistical techniques. We assume this is caused by the trend in new data generation within the last years. [8] claims although analytics does not reduce the volume of decisions, it enables a decision-maker or organisation to control and monitor the decision basis, which suggests that decision quality increases if the decision concerns issues that rest on statistics and facts. 


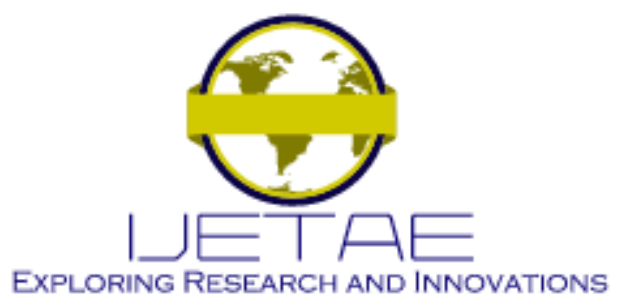

International Journal of Emerging Technology and Advanced Engineering

Website: www.ijetae.com (E-ISSN 2250-2459, Scopus Indexed, ISO 9001:2008 Certified Journal, Volume 11, Issue 07, July 2021)

The practical problems of decision making in operations management of engineering systems is discussed by [9]. He claims, these problems are characterized by two specific attributes: 1) continuous decision-making over time under dynamically changing environments and 2) a competition against an opponent. As per his study the adaptation to the changes in the problem settings by effectively countering the opponent strategy is critical for successful decisions. In our study we consider other organizational units outside engineering team as opponents in engineering project decision-making and analytical reports are the means of this countering.

\section{TheOretiCAL BACKGROUND FOR CLUSTER ANALYSIS}

In cluster analysis, we partition the set of the collected data into groups based on data 'similarity and then assign the labels to the groups [10]. The aim of such operation is to organize the heterogenous data set into more homogenous sub-sets to allow for more meaningful data interpretation.

Although there are various clustering techniques available this study is focused on the hierarchical one. The input of hierarchical clustering is a weighted graph whose edge weights represent pairwise similarities or dissimilarities between data points; and it is represented by a rooted tree where each leaf represents a data point and each internal node represents a cluster containing its descendant leave [11].

Although the data interpretation is present on the cluster level, often the cluster processing algorithm starts from bottom - on the level of single objects where the two objects with the shortest distance are merged. Step-by-step program merges these objects into clusters until the predefined criteria is met (for example the number of clusters or criteria for similarity). At that moment the clustering algorithm stops. This process is called agglomerative clustering. In this case clustering assigns the objects to the particular clusters based on the measuring of distance vector in n-dimensional space [12].

There are several ways of distance measuring. One of them is Ward's one where the distance D between two clusters $\mathrm{K}, \mathrm{L}$ is defined as:

$$
D_{K L}=\frac{\left\|\bar{X}_{K}-\bar{X}_{L}\right\|}{\frac{1}{N_{K}}+\frac{1}{N_{L}}}
$$

$n$ is the number of observations

$v$ is the number of variables

$x_{a}$ is the its observation

$C_{K}$ is the $K$ th cluster, subset of $\{1,2, \ldots, n\}$

$N_{K}$ is the number of observations in $C_{K}$

$x$ is the sample mean vector

$x_{K}$ is the mean vector for cluster $C_{K}$

$\|x\|$ is the square root of the sum of the squares of the elements of $\mathrm{x}$ (the Euclidean length of the vector $\mathrm{x}$ )

The above formulation of distance measuring however, is applicable for numerical (continuous) data only. The problem of processing categorical data is more complex, i.e. we can say 100 hours of work is more than 10 hours one, but how we will compare the utility of $10 \mathrm{~h}$ spent on the replacement of shaft vs. the same amount of time spent on fixing engine control software bug causing vehicle fails to start? Which of these two problems is more important?

Most pioneers of solving mixed numeric and categorical value for clustering problem is to redefine the distance measure and apply it to existing clustering algorithms, e.g. K-prototype applies Euclidean distance to numeric attributes and a distance function is defined to be added into the measure of the closeness between two objects [14]. Instead of just using the distance between objects another metric called similarity measure is introduced to the model and the distance formula is as follows:

$$
d\left(X_{i,} Z_{i}\right)=\sqrt{\sum_{j=1}^{m_{r}}\left(x_{i j}^{r}-z_{i j}^{r}\right)^{2}+Y_{t} \sum_{j=1+1}^{m_{c}} \delta\left(x_{i j}^{c}-z_{i j}^{e}\right)^{2}}
$$

Depending on the type of similarity measuring in distance matrix Ahmad [15] in his survey lists 8 different hierarchical clustering algorithms, appropriate for the processing of mixed data that he further treat them in three major categories. Most of them are based on agglomerative clustering category. There are also other approaches to processing of mixed variables, like fuzzy clustering [16] or kernel density estimation [17 however; these are based on the concept of similarity matrix as well.

Although the core of our study is the cluster analysis, to see a big picture and to briefly review if our results make sense the traditional statistic techniques are used. For that purpose, we have used the following statistical parameters: number of members in the group, mean, median, mode, standard deviation (STD), range, skewness, and kurtosis. 


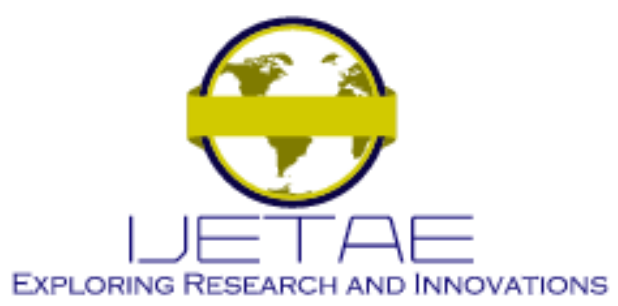

International Journal of Emerging Technology and Advanced Engineering

Website: www.ijetae.com (E-ISSN 2250-2459, Scopus Indexed, ISO 9001:2008 Certified Journal, Volume 11, Issue 07, July 2021)

As these are not in prime concern of this paper for more details on their meaning and mathematical formulation please refer to [18].

\section{Methodology}

The idea behind the methods used here is to search for commonalities within the virtual groups of projects (clusters) identified as similar by the cluster analysis. This approach represents the alternative to the traditional data analysis based on relationships to the functional unit or discipline where the relevant projects are managed. Based on the research findings the concern is to propose the effective measures towards improving the project management process, data management and functional strategies within the analysed organizational unit (i.e. engineering unit) as well as to suggest the measures toward other involved organizational units and the whole analysed organization..

In the study we use the "SMART" approach [19] to the data in order to capture and analyse them more effectively . This approach (Figure 1) starts with a strategy in order to identify the areas in which our data analysis can make the biggest difference to the project performance.

The theoretical framework on strategy comes mainly from the studies on project management, organizational decision-making and analytics described in earlier sections. In principle, the analytical part of strategy formulation is based on using hierarchical clustering with support of traditional descriptive statistics, where we analyse the raw data retrieved from corporate information systems, however there are also some limitations of this concept. [20]), [21] claim the efficient use of analytics is determined by the level of organizational analytical maturity. Additionally, [22] highlights the political aspects of using analytics in organization. As we do not use a single source of data there is a problem of data validity.

Once the strategic questions are answered we can look at the variables - analysed data and their metrics. Metrics must be established for those critical activities that can have a direct impact on the success or failure of the project [23]. This includes the tracking of assumptions and value. Insufficient or ineffective metrics prevent us from understanding what decisions really need to be made. As soon as we are clear on targets and relevant metrics, we can proceed with the data analysis, followed by interpretation (reporting) and change introduction (transform the business).
Data analysis represents the core of the research. Due to the nature of the data, i.e. both continuous and categorical variables we are limited in the available clustering methods [24]. With consideration of the software tools (JMP Pro from SAS used $($ ) we have chosen the hierarchical clustering method with the Fast Ward algorithm that is generally quite well accepted by researchers around the world. The categorical data transformation was performed using a pre-built tool in the program. In order to briefly review the inputs data and roughly validate the results of cluster analysis we have calculated basic descriptive statistics using [25].

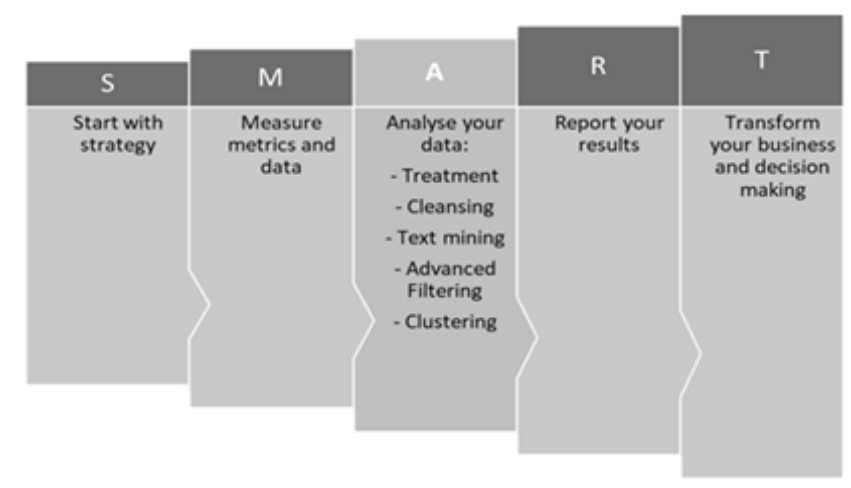

Figure 1. SMART approach

\section{APPLICATION PART}

As already discussed in the previous section the strategy of our research comes from the fundamental need to improve the internal engineering projects performance (shorten the average project slippage) within the surveyed organization. To do so we had to take the following steps:

- Define the data sources

- Establish the proper metrics of project performance

- Gather, clean and standardize the available data

- Use the analytical techniques for discovery of a hidden patterns in these data that are likely to influence a projects slippage

- Quantify the impact of these "patterns“ on the projects performance to the extent it is possible

- Specify the assumptions and limitations of the study

- Based on the results of this analysis to suggest a set of recommendations to improve the overall projects performance

- Suggest the recommendations for future research, development and technical improvements. 


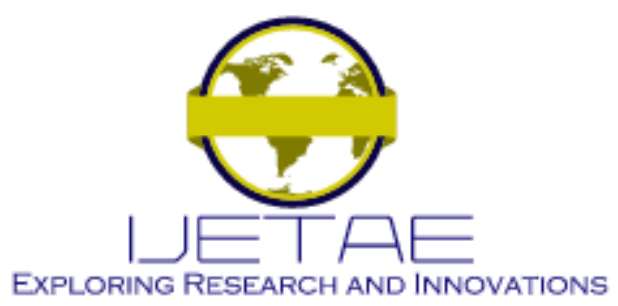

International Journal of Emerging Technology and Advanced Engineering

Website: www.ijetae.com (E-ISSN 2250-2459, Scopus Indexed, ISO 9001:2008 Certified Journal, Volume 11, Issue 07, July 2021)

Considering all above factors, we have formulated of our strategy. Here we have considered phenomena like inconsistent processes, software heritage - several generations of software working in parallel creating a data silos, level of project management maturity, information overload of the staff, political behaviour of managers, and specially complexity of the projects.

Based on the above consideration we have defined the following alerts for the data analysis and interpretation:

- Specify the analysed data sets and variables

- Access all five relevant corporate information systems and download the completed engineering projects between 2017 - 2020.

- Export all these data into the .cvv format

- Merge into single file

- Access this file, remove the duplicate projects and those where any of the key analysed variables missing

- Create the filters for measured variables and generate the separate files as per these filters in addition to the master file

- Import all these files into descriptive statistic calculator and calculate the parameters (see results chapter for the list of parameters)

- Import master file into JMP Pro and setup for hierarchical clustering

- Download the list of cluster members and dendrogram

Once the strategy has been defined, we have chosen for variables to operate with. From the source systems we were able to retrieve 90 various metrics falling into 5 categories: overall project information, data on scheduling and project progress, technical information, project controlling data and warranty data on the vehicles already delivered to client (Table I). These metrics are measured in various units, e.g. days, percentage, manhours or in nominal categories (text).

As we aimed to analyse the project slippage mechanism with respect to the available computing power, we have chosen 5 parameters assumed to be the most representative to be monitored. These parameters are: vehicle brand (carline), engineering department involved, system within a vehicle, project slippage and impact (importance of project). One of them (project slippage / delay) as a metric of performance. The other parameters were chosen based on subject matter expert advice as these are believed the most representative measures for remaining project constraints where the brand is associated with the product, department corresponds to resources; system and impact (prioritization) reflect the ancillary needs.

Most of analysed parameters are represented by categorical data, usually nominal (e.g. engineering department can be powertrain, electrical, chassis, etc.), except the importance of the project that is represented by nominal variable where 1 is a low importance while the 5 represents the critical importance. The only continuous parameter is the project slippage that is measured in days.

TABLE I

AVAILABLE DATA METRICS

\begin{tabular}{|l|l|}
\hline I. Overall & II.Scheduling \\
\hline Lead Vehicle & Pending period \\
\hline Model Year & Date : Original Open \\
\hline Platform & Target Pend Date \\
\hline Brand & Target Pend Phase \\
\hline Affected Programme & Date : Pending \\
\hline Severity & Slippage \\
\hline Risk & Pending period \\
\hline Impact & Late to pend \\
\hline Supplier & D1 planned \\
\hline Supplier Site & D1 actual \\
\hline QSF & D2 planned \\
\hline III.Technical & D2 actual \\
\hline Motorization & D3 planned \\
\hline Original CoC & D3 actual \\
\hline Engineering department & D4 planned \\
\hline Support CoC & D4 actual \\
\hline System & D5 planned \\
\hline Issue Title & D5 actual \\
\hline Issue Description & D6 planned \\
\hline Root Cause & D6 actual \\
\hline Problem Definition & D7 planned \\
\hline Interim containment & D7 actual \\
\hline Containment in place & D8 planned \\
\hline Function Name & D8 actual \\
\hline Emergency Response & ERA Date \\
\hline Interim Action & Resolve Start Date \\
\hline Permanent Action & Acceptance Criteria Date \\
\hline & \\
\hline
\end{tabular}




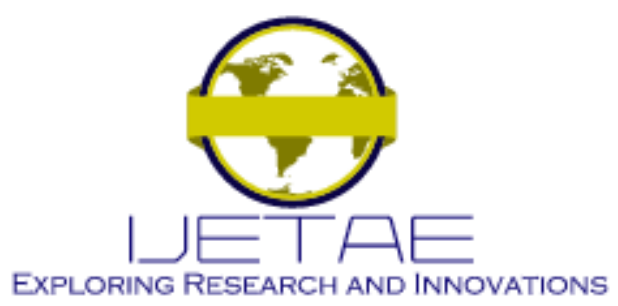

International Journal of Emerging Technology and Advanced Engineering

Website: www.ijetae.com (E-ISSN 2250-2459, Scopus Indexed, ISO 9001:2008 Certified Journal, Volume 11, Issue 07, July 2021)

\begin{tabular}{|c|c|}
\hline IV.Project control & Reaction Plan Date \\
\hline State & Repair Containment Date \\
\hline Activity & Planned Closure Date \\
\hline Build Phase & Actual Closure Date \\
\hline Type & Parts Av Planned Date \\
\hline Impact & Parts Av Actual Date \\
\hline Process Owner & Project Close Date \\
\hline Project CSS & V. Warranty \\
\hline SST & Scorecard 12MIS R/1000 \\
\hline VFG & Scorecard 3MIS R/1000 \\
\hline Team Leaders & Scorecard 0MIS R/1000 \\
\hline Project Creation Date & Scorecard 12MIS A/1000 \\
\hline Project Start Date & Component Name \\
\hline FPS Workgroup & Subcomponent Name \\
\hline Operation & Fault Name \\
\hline Overall Status & \\
\hline Containment Status & \\
\hline PCA (D6) Status & \\
\hline Confidence\% & \\
\hline Containment VIN & \\
\hline Closure VIN & \\
\hline Top Concern & \\
\hline Detection Rating & \\
\hline Parts Av Comments & \\
\hline
\end{tabular}

The next step involved the analytical part. The surveyed data were retrieved from several internal corporate databases that serve the daily tasks of engineering and quality department. The raw data were consequently cleansed prior to analysis. The data cleansing process included in this case merging the data from various sources into a single file and single format, check for duplicates or inconsistency, filtration based on attributes and other preparatory works described further. After the merging and cleaning data from various sources we received the list of over 2000 projects that we used as a base for our study. Next step was the data optimization by vectorizing.

Text vectorization is the process of mathematically representing text in a lower-dimensional space with a few hundred dimensions, improving the performance of machine learning models, in other words to decrease the computer processing time. In this step we also reduced the processing time of the analysis. Vectorized file from Dcipher we imported into JMP Pro for the hierarchical cluster analysis. The outputs of this analysis are the list of cluster members and a graphical representation of clusters called dendrogram (Figure 2). After this step the statistical analysis turns into the knowledge-based or technical ones as we start to search for commonalities within the particular clusters. This part of the work is more manual, however supported by numerous graphs and statistics.

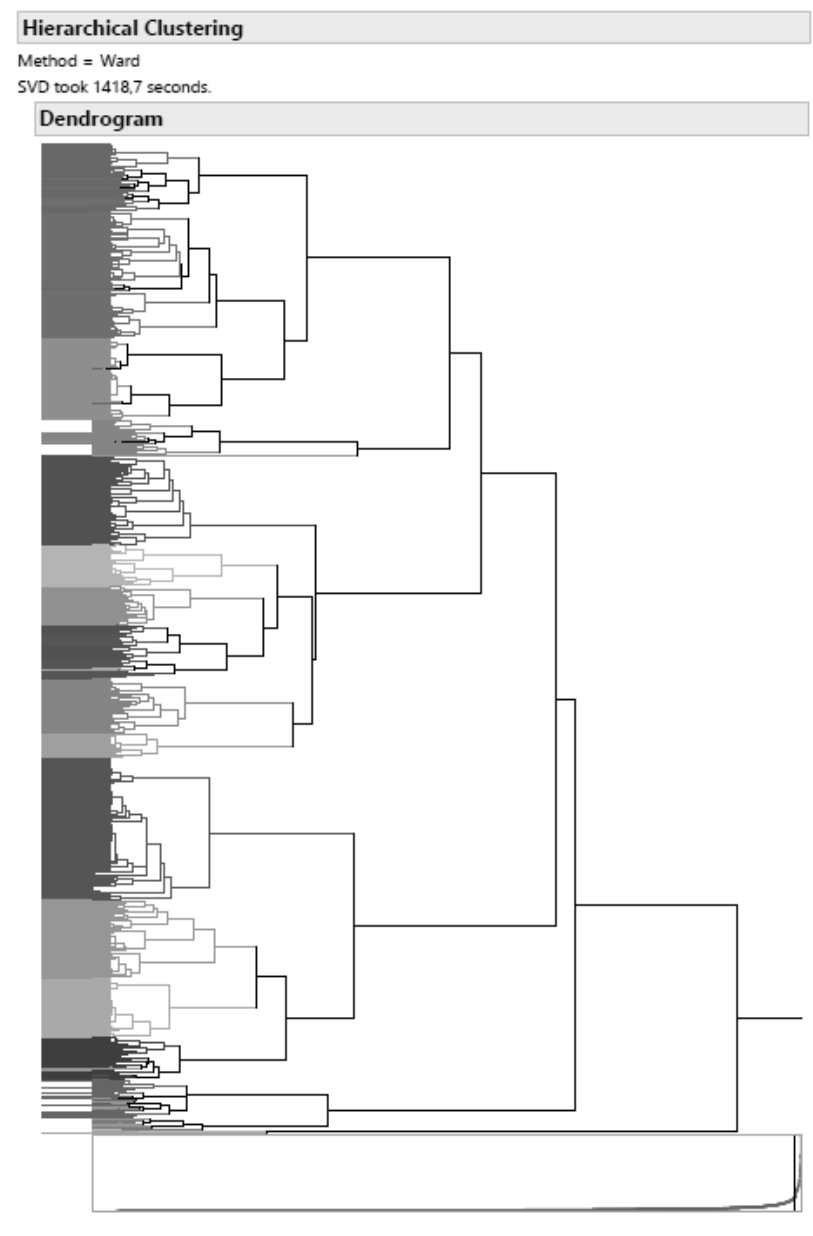

Figure 2. Dendrogram 


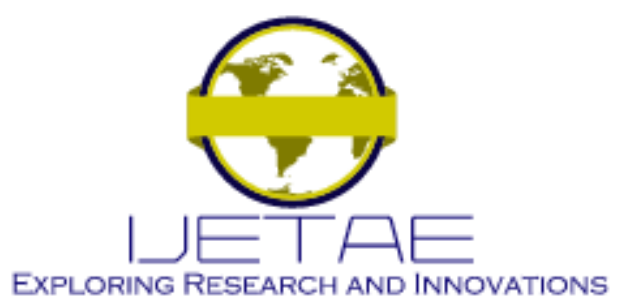

International Journal of Emerging Technology and Advanced Engineering

Website: www.ijetae.com (E-ISSN 2250-2459, Scopus Indexed, ISO 9001:2008 Certified Journal, Volume 11, Issue 07, July 2021)

\section{RESULTS}

Prior to the cluster analysis itself we have visualized the data set and calculated basis descriptive statistics in order to get the brief overview of the project performance and structure. As depicted on (Figure 3) the majority of projects is closed with 0 days slippage. Here we are suspicious as it might indicate the artificial or formal closing of projects that might not necessarily be resolved at the same day. Additionally, Table II presents the statistical data calculated on the analysed data set (column Whole) and major engineering disciplines involved where we can see the vast majority of projects falls into categories Body and Electrical engineering. This is not surprising in case of luxury vehicles manufacturer where the vehicles are equipped with advanced electronic systems and many comfort related components. What is worth of note here is even these systems / components are usually complex in average these projects are completed ahead of schedule. This might indicate the overestimated planning in organization.

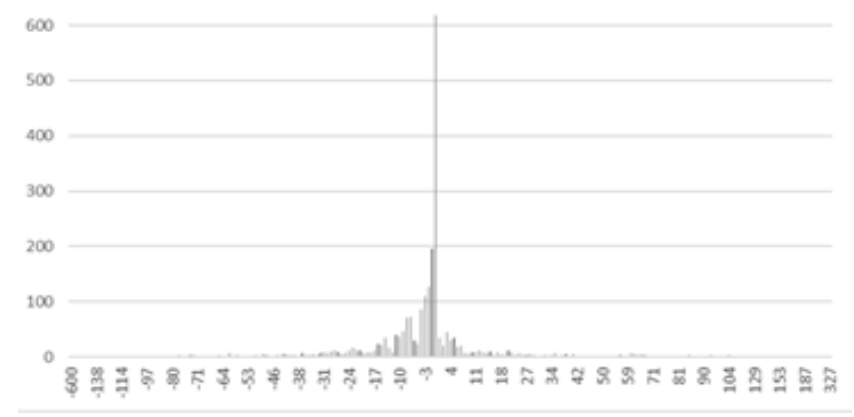

Figure 3. Histogram of projects slippage

TABLE II

STATISTICS OF THE ANALYSED DATA SET

\begin{tabular}{|l|l|l|l|l|l|}
\hline & & & & & \\
Param. & Whole & Elect & PWT & PWT & Chassis \\
\hline Members & 2057 & 732 & 816 & 319 & 105 \\
\hline Mean & $-1,48$ & $-5,13$ & $-2,08$ & 4,69 & $-0,23$ \\
\hline Median & -1 & -2 & -1 & 0 & 0 \\
\hline Mode & 0 & 0 & 0 & 0 & 0 \\
\hline STD & 35,4 & 41,82 & 31,23 & 35,57 & 33,42 \\
\hline Skewness & $-0,85$ & $-2,98$ & $-0,35$ & 3,32 & $-0,8$ \\
\hline Kurtosis & 57,74 & 65,45 & 41,77 & 25,67 & 11,97 \\
\hline Range & 927 & 836 & 638 & 417 & 290 \\
\hline
\end{tabular}

Based on the results of hierarchical clustering we have identified 20 project categories involving the projects with certain level of similarity. We can observe the hierarchical method tends to merge clusters of comparable size. In line with our expectations (we search for inter-disciplinary issues causing project slippage) we have identified many multi-discipline clusters. They are either "truly" multidisciplinary, e.g. involving electrical, powertrain, logistics, etc.; or at least single discipline with various systems involved, e.g. cluster A (Table III) where all 111 cluster members are the projects from electrical discipline that can be further distinguished into another 10 sub-systems. Majority of the projects in this cluster is associated with the wiring, however there are also automated driver assistance (ADAS), multimedia (especially audio and voice), driver information and few other advanced electronics projects included here. From the technical perspective we can assume those electronic systems are also linked with wiring projects as all electronics need to be powered by electricity.

As opposite to single discipline clusters however, we have identified few single-discipline clusters, e.g. projects including seats only.

As the number of clusters is behind the scope for this survey, we have focused just on 2 clusters with the highest average delay of its projects that are called cluster A and B.

TABLE III

STRUCTURE OF CLUSTER A

\begin{tabular}{|c|r|}
\hline Cluster A & No. of members \\
\hline Electrical_Engineering_ & 111 \\
\hline Special Systems & 1 \\
\hline Wiring & 75 \\
\hline Body Modules & 1 \\
\hline Multimedia & 8 \\
\hline Vehicle Dynamics & 2 \\
\hline Climate Electronics & 1 \\
\hline Driver Information & 3 \\
\hline Switches \& Controls & 3 \\
\hline ADAS & 14 \\
\hline Connected Car & 3 \\
\hline
\end{tabular}

When we compared the statistics of clusters A \& B (table III-V) with the most populated ones in our study and with the whole population, we have found that mode, range and median is more-less comparable for all of them. 


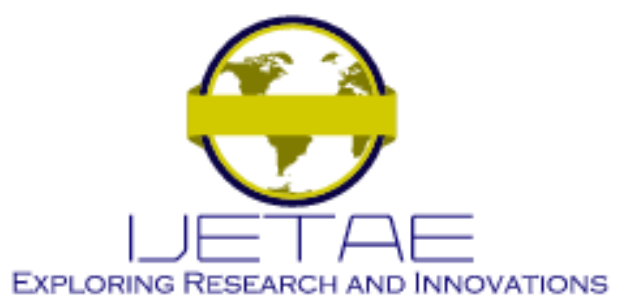

International Journal of Emerging Technology and Advanced Engineering

Website: www.ijetae.com (E-ISSN 2250-2459, Scopus Indexed, ISO 9001:2008 Certified Journal, Volume 11, Issue 07, July 2021)

Analysed clusters are obviously characterized by high mean, but surprisingly by low kurtosis too. This might indicate a higher impact of outliers on the cluster performance. With consideration of low kurtosis for both clusters we can really assume their performance is highly influenced by outliers rather than generally inaccurate planning. Therefore, we can assume the slippages are caused by project complexity rather than by overloaded department.

TABLE IV

STRUCTURE OF CLUSTER B

\begin{tabular}{|l|r|}
\hline Cluster B & No. of members \\
\hline Powertrain_Engineering_ & 249 \\
\hline Petrol engine & 3 \\
\hline Drivetrain & 9 \\
\hline Transmission & 11 \\
\hline Powertrain control unit & 14 \\
\hline Diesel engine & 2 \\
\hline Air inlet & 6 \\
\hline Cooling & 31 \\
\hline Exhaust & 36 \\
\hline Various sensors & 15 \\
\hline Hybrid & 10 \\
\hline Calibration & 9 \\
\hline Transition & 8 \\
\hline Battery system & 31 \\
\hline Start up & 26 \\
\hline DC systems & 9 \\
\hline Control power & 29 \\
\hline
\end{tabular}

The performance of the cluster A is highly influenced by long-delayed projects, while in cluster B involving inhouse engineering for power supply systems and cooling prevail medium length slippages. Considering this data we can assume the electrical wiring including battery and engine startup cables, seats, cooling and exhaust system contain the projects that are either likely to be delayed or very diverse in terms of completion date.
TABLE V

ANALYSED CLUSTERS

\begin{tabular}{|l|c|c|}
\hline Parameter & Cluster A & Cluster B \\
\hline Size & 111 & 249 \\
\hline Mean & 13,1 & 4,57 \\
\hline Median & -2 & 0 \\
\hline Mode & 0 & 0 \\
\hline STD & 54,58 & 30,29 \\
\hline Variance & 2977,54 & 918,46 \\
\hline Minimum & -92 & -90 \\
\hline Maximum & 236 & 153 \\
\hline Range & 328 & 243 \\
\hline Skewness & 2,47 & 1,6 \\
\hline Kurtosis & 8,65 & 9,07 \\
\hline
\end{tabular}

If we compare these the above systems with the disciplines (Tab. I) we will see the wiring accounts for over $40 \%$ of all electrical projects, however there is no proportionality found here. The wiring sub-system has its statistical mean close to 0, multiple times lower kurtosis, positive skewness, higher kurtosis, lower STD and much lower range comparing to the whole electrical discipline. In general, it means the wiring sub-system has more accurate resource utilization (less projects completed ahead of schedule), lower impact of projects artificially closed right on time, but the projects tend to be more delayed comparing to the electrical average. We can also see the cluster A is not really proportional to the wiring sub-system in terms of project structure. The cooling \& exhaust projects are even less likely to be delayed than the powertrain sub-system.

Based on the above observations we have found the results of cluster analysis in general do not correspond with the findings when each sub-system analyzed separately, especially in case of diverse and multi-disciplinary projects. The cluster results are also found to be more affected by outliers. 


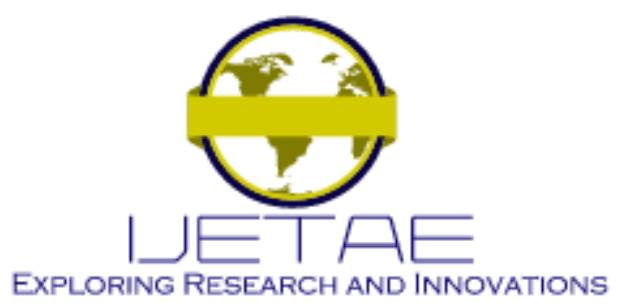

International Journal of Emerging Technology and Advanced Engineering

Website: www.ijetae.com (E-ISSN 2250-2459, Scopus Indexed, ISO 9001:2008 Certified Journal, Volume 11, Issue 07, July 2021)

\section{DISCUSSION}

Our study shows how challenging task is to keep the set of a diverse and cross-functional engineering projects on track, even in case of the analytically matured organization with advance project management system in place and pressure put on the performance metrics and accomplishment of the goals is applied by management.

The research is based on the following assumptions and simplifications: the analysed five variables represent the principal components of the data set (are major contributors to the project performance while most of other ones are just supplementary or redundant); project prioritization using importance factor 1-5 is based on rational decision-making by management, factor of team overload is neglected, data are accurate and valid, problems were properly described. The problem we have also faced are associated with the available technology and computing power; input data quality or artificial closing of projects in order to meet the prescribed metrics is captured. On the top of that there are many others not considered, i.e. particularities of organizational culture and styles of decision-making that are very difficult to measure and therefore, hard to fit into the model and even outside of scope for this technical paper.

The methodology offers an alternative to the traditional data analysis within the organization. As opposite to parallel data analysis within functional units and disciplines, e.g. split the analysed corporate data into the ones from particular factories and further down into departments; the cluster analysis looks for hidden complex relationships between variables so it may bring more valuable reporting, especially in large organizations with the complex products like automotive. This is especially the case in the age Fourth industrial revolution and Internet of Things.

The strategy was mainly determined by the availability and quality of data sources, available resources and organizational context. Within the organizational context we have considered mainly the following factors: immature organization with a purely established internal processes, software heritage where several generations of software operates in parallel and creating various data silos, generic material used for several carlines and production plants makes it difficult to introduce the change or innovation, political behaviour of managers or complex problems with the limited possibilities measuring the improvement.
The resource utilization (floating) in this paper is based on the evidence of un-proportional project performance where more than half of all projects completed ahead of schedule or artificially right on time therefore, the re-design shall cope the challenges like focus on complex planning, real closure dates for the projects and environment external to organization.

Out of over 90 available data metrics in our projects we have considered the following five of them have the critical impact on our study: vehicle brand, engineering discipline leading the project, vehicle system, project slippage, importance of project for organization. In fact, only the project slippage and importance are really measurable metrics, all the others are categorical data, therefore we had to identify an appropriate methodology for the processing of such kind of data. We have used the hierarchical method with the Ward's algorithm that is built in methods within the JMP Pro software from SAS $®$ we used in our study. While this method is designed to work with all types of data, i.e. continuous, nominal and ordinal, it has some drawbacks like sensitivity to the outliers, absence of trainer/supervisor to validate the results and uncertainty in allocation of objects to the clusters.

The study is undertaken on the set of over 2000 projects, therefore we consider the results as really representative. These analysed projects were extracted from various corporate data sources, filtered for purpose and data completeness. We have filtered for the projects from serial manufacturing and matured pre-serial production phases in order to minimize the effect of prototyping and specific engineering issues on the project management metrics. For the same reason we have removed the duplicities and projects with the incomplete data. Consequently, these data were pre-processed and analysed.

In addition to the above observation and assumptions there are few more aspects to discuss. The analysis shows variable completion dates of the projects concerned with outsourced equipment as well as evidence of unreasonable delays associated with complex in-house engineering that are not sufficiently explained. The model is mainly focused on the internal project data with the limited consideration of external environment and supply chain. 


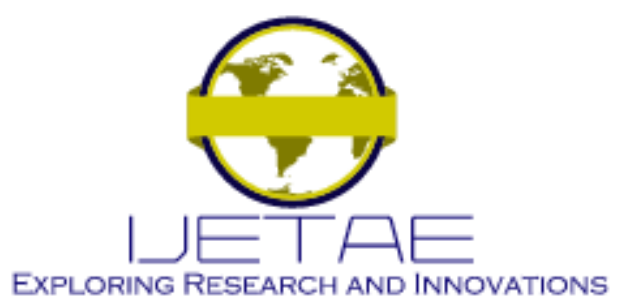

International Journal of Emerging Technology and Advanced Engineering

Website: www.ijetae.com (E-ISSN 2250-2459, Scopus Indexed, ISO 9001:2008 Certified Journal, Volume 11, Issue 07, July 2021)

\section{CONCLUSIONS}

The core of our study is the cluster analysis. Using the advanced statistical tools and techniques we have searched here for the clusters of similar projects and some hidden relationships within these clusters in order to identify the common causes of project slippage. The idea behind is to identify the complex and inter-disciplinary issues, that expand outside the traditional data analytics designed on functional principle where the reporting is bounded by the functional unit like engineering, logistics, etc. The algorithm for hierarchical method has split the set of our projects into 20 clusters based on the similarity

In terms of structure we have identified both the single sub-system clusters as well as more complex ones made of projects from different disciplines or at least of more subsystems of the same engineering discipline. A typical example is the cluster A made of projects from 11 subsystems. From the data processing point of view, we perceive the complex clusters positively as they indicate the method takes into consideration several analysed variables and it is not strongly biased by a single one. It allows us to investigate them in a broad context, i.e. we can search for the common sources of delays that are present across several engineering disciplines. Such results in general do not correspond with the findings when each discipline or sub-system represented within the cluster are analysed separately.

In our study we have particularly focused on the complex clusters called here A, B with the highest average slippage of all project in this clusters. Cluster A with the average slippage of above 13 days is dominated by wiring projects, followed by advanced electronic systems like ADAS, multimedia, etc. Therefore, we strongly recommend to focus the corporate senior management attention on the coordination of advanced electronic projects with the related wiring ones (power supply and control cables for these systems) from the early beginning in order to avoid any linear supply chain problems where the late engineering change and upgrade implemented in ADAS, multimedia, etc. system is reflected into the wiring projects with the delay multiplication. The performance of cluster B is strongly affected by battery, power supply and battery charging Both clusters are charged by a number of outliers - cooling \& exhaust sub-system projects of a long slippage.
On complex clusters in general we assume the project performance might be significantly improved here by focusing on multi-disciplinary coordination (perhaps on senior management level), more efficient involvement of suppliers into the project teams and more attention to inhouse CAD design.

In reference to the result of our study we assume the clustering may be a useful tool in effort to design for the flat organizational structures and multifunctional teams formed by internal and external staff in order to cope the inter-disciplinary and complex problems. On the other hand we have observed a high sensitivity of these techniques on data outliers, therefore we recommend to direct the further research and development on a robust data pre-processing in order to improve the accuracy of the results as well as the extremely long processing time. In order to address the concern of real time data we also suggest another research and development in the fields of computing hardware and development of fast algorithms.

Although the study has been mainly focused on two clusters with the highest average project slippage, our general observation in the study is the proportion of the projects with the negative delay (completed ahead of time) to the whole cluster size is floating around $40-60 \%$ in most all 20 clusters, that generally indicates a significant inaccuracy in resource allocation that should be addressed as a major issue for future planning optimization strategies. For this over-estimation of resource utilization, we have not found any correlation with technical discipline, department involved, size of the analysed cluster or even expected project complexity.

As part of the preparatory works for our study (data collection) we have also performed a questioning of leaders and managers on various levels of organization structure in order to understand the organization environment and level of analytical maturity in studied organization. As a secondary product of this survey we have empirically proofed other studies of organizational decision-making reporting that formal data analysis is used not only to get informed decisions but also for political reasons not encompassed by the rational approach and documents many studies in which formal analysis is used to support already made choices and to advocate for a specific coalition over another. [22]. 


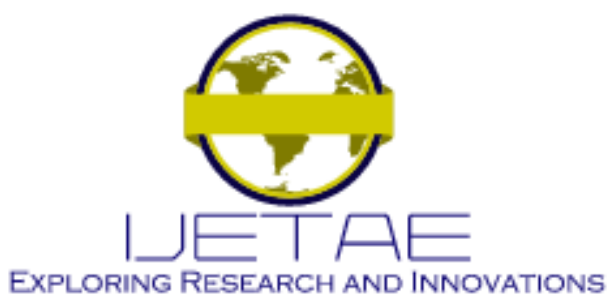

International Journal of Emerging Technology and Advanced Engineering Website: www.ijetae.com (E-ISSN 2250-2459, Scopus Indexed, ISO 9001:2008 Certified Journal, Volume 11, Issue 07, July 2021)

We need to highlight this danger for a qualified and efficient use of analytics and reporting within the organization as any innovative reporting techniques may unintentionally support such activities within the organization.

\section{REFERENCES}

[1] Bowen, H. K. 1996. Project Management Manual. Harvard Business School. Background Note 697-034.

[2] Kerzner, H. 2009. Project management: A systems approach to planning, scheduling, and controlling (10th ed.). New York: John Wiley \& Sons.

[3] Meredith, J., Mantel, S. 2010. Project management: A managerial approach 7th edition. 7th ed. New York: Wiley.

[4] Ain, N., Vaia, G., Delone, W. H., Waheed, M. 2019. Two decades of research on business intelligence system adoption, utilization and success - A systematic literature review. In Decision Support Systems, Volume 125.

[5] Ni, F., Arnott, D., Gao, S. 2019. The anchoring effect in business intelligence supported decision-making. In Journal of Decision Systems, 28:2, 67-81.

[6] Retnowardhani, A., Sardjono, W., Triana, Y. S. 2019. Review Study of Business Intelligence to Support Strategic Decision Making. In International Conference on Electrical Engineering and Informatics (ICEEI) July 2019, 9 - 10, Bandung, Indonesia.

[7] Brandt, T., Wagner, S., Neumann, D. 2021. Prescriptive analytics in public-sector decision-making: A framework and insights from charging infrastructure planning. In European Journal of Operational Research, Volume 291, Issue 1, p. 379-393.

[8] Berhane, A., Nabeel, M., Grosse, C. 2020. The Impact of Business Intelligence on Decision-Making in Public Organisations. In IEEE International Conference on Industrial Engineering and Engineering Management (IEEM), pp. 435-439.

[9] Bayrak, A. E., Christopher McComb, C., Cagan, J., Kotovsky, K. 2021. A strategic decision-making architecture toward hybrid teams for dynamic competitive problems. In Decision Support Systems, Volume 144, 113490.
[10] Wlodarczyk, K., Kingsley, I. S. 2020. Data Mining Project: Cluster Analysis and Dimensionality Reduction in R using Bank Marketing Data Set. 2020.

[11] Cohen, V. et al. 2019. Hierarchical Clustering: Objective Functions and Algorithms. J. ACM 66, 4, Article 26 (June 2019), 42 pages.

[12] SAS Institute Inc. 2018. JMP® 14 Multivariate Methods. Cary, NC: SAS Institute Inc

[13] Ji, J. et al. 2020. Clustering Mixed Numeric and Categorical Data With Cuckoo Search," in IEEE Access, vol. 8, pp. 30988-31003.

[14] Shih, M., Jheng, J., Lai, L. 2010. A two-step method for clustering mixed categroical and numeric data", Tamkang J. Sci. Eng., vol. 13, no. 1, pp. 11-19, 2010.

[15] Ahmad, A., Khan, S. S. 2019. Survey of State-of-the-Art Mixed Data Clustering Algorithms," in IEEE Access, vol. 7, pp. 3188331902.

[16] D’Urso, P., Massari, R. 2019. Fuzzy clustering of mixed data, Information Sciences, Volume 505.

[17] Dinh, D., Huynh, V., Sriboonchitta, S. 2021. Clustering mixed numerical and categorical data with missing values Information Sciences, Volume 571, 2021, Pages 418-442.

[18] McClave, J.T., Benson, P.G., Sincich, T. 1998. Statistics for Business and Economics. Prentice Hall.

[19] Marr, B, Von Scheel, H. 2015. Big Data: Using SMART Big Data, Analytics and Metrics To Make Better Decisions and Improve Performance. Wiley.

[20] Boyer, J. at al. 2010. Business Intelligence Strategy: A Practical Guide for Achieving BI Excellence. IBM corporation. 2010. 137p.

[21] Davenport, T. H.. 200810 Principles of the New Business Intelligence. In Harvard Business Review.

[22] Shollo, A. 2013. The Role of Business Intelligence in Organizational Decision-making. Frederiksberg: Copenhagen Business School.

[23] Kerzner, H. 2011. Project management metrics, KPIs, and dashboards: a guide to measuring and monitoring project performance. Hoboken, N.J., Wiley.

[24] Shmueli, G. et al. 2017. Data Mining doe Business Analytics: Concepts, Techniques, and Applications in R. John Wiley \& Sons.

[25] https://www.calculatorsoup.com/calculators/statistics/descriptivestati stics.php. 